\title{
Eficiência dos gastos públicos com segurança nos municípios baianos em 2018
}

\author{
Manoel Alexandre de Lucena ${ }^{1}$ \\ Wescley de Freitas Barbosa ${ }^{2}$ \\ Eliane Pinbeiro de Sousa $a^{3}$
}

\begin{abstract}
Resumo: A criminalidade se tornou um dos maiores problemas sociais brasileiro no período recente, gerando um custo social ao impedir o desenvolvimento de atividades econômicas, como também redução na qualidade de vida advinda pelos danos morais e perdas de vidas. No Nordeste brasileiro e, particularmente, na Bahia, este problema tem sido mais evidente, sendo relevante investigar a alocação dos recursos públicos destinados ao combate da criminalidade. Desta forma, este estudo se propõe analisar a eficiência dos gastos públicos municipais com segurança na Bahia. Para tal, utilizou-se o método de Análise Envoltória de Dados (DEA) sob a orientação produto, cujos insumos foram obtidos junto ao Sistema de Informações Contábeis e Fiscais do Setor Público Brasileiro e os produtos foram extraídos da Secretaria de Segurança Pública da Bahia, ambos para o ano de 2018. Os resultados indicam que parcela majoritária da amostra de municípios baianos analisados está aplicando o insumo de modo indevido. Constata-se também que não necessariamente os maiores dispêndios realizados com segurança pública promovem melhores níveis de eficiência.
\end{abstract}

Palavras-Chave: Alocação dos recursos públicos. Criminalidade. DEA. Gestão em segurança.

\section{Efficiency of public spending on security in municipalities in the state of Bahia in 2018}

\begin{abstract}
The criminality has become one of the biggest social problems in Brazil in the recent period, generating a social cost by preventing the development of economic activities, as well as a reduction in the quality of life resulting from moral damages and loss of life. In the Brazilian Northeast and, particularly, in Bahia, this problem has been more evident, being relevant to investigate the allocation of public resources destined to fight crime. Thus, this study aims to analyze the efficiency of municipal public spending on security in Bahia state. The output-oriented Data Envelopment Analysis (DEA) method was used, with inputs from the Brazilian Public Sector Accounting and Tax Information System and outputs from the Public Security Secretariat of the State of Bahia, considering the year 2018. The results indicate that, in its majority, the sample of municipalities of Bahia state analyzed is applying inputs improperly. It was also found that the highest expenditures on public security do not necessarily promote higher levels of efficiency.
\end{abstract}

Keywords: Allocation of public resources. Crime. DEA. Public security management.

\footnotetext{
1 Graduando em Ciências Econômicas pela Universidade Regional do Cariri (URCA) e Bolsista de Iniciação Científica BPI FUNCAP. E-mail: manoelalexx123@gmail.com.

2 Doutor em Economia pela Universidade Federal do Ceará (UFC). E-mail: barbosa.wescley@gmail.com.

3 Pós-Doutora em Economia Aplicada pela Escola Superior de Agricultura Luiz de Queiroz da Universidade de São Paulo (ESALQ/USP), Professora Associada do Departamento de Economia da Universidade Regional do Cariri (URCA) e Bolsista de Produtividade em Pesquisa, Estímulo à Interiorização e à Inovação Tecnológica (BPI) da Fundação Cearense de Apoio ao Desenvolvimento Científico e Tecnológico (FUNCAP). E-mail: pinheiroeliane@hotmail.com.
} 


\section{Introdução}

No Brasil, nos últimos anos, o nível de violência tem apresentado significativo crescimento. Em 2017, observou-se o maior nível histórico de letalidade violenta intencional do País. Ademais, destaca-se que de, 2007 a 2017, é possível observar uma heterogeneidade na evolução desse indicador quando analisado de forma desagregada por região. Enquanto no Centro-Sul do País esses dados estão estáveis ou com leve redução, no Norte e Nordeste o cenário é de expansão (CERQUEIRA et al., 2019). Face esse crescimento da violência, ganha relevo as discussões acerca da gestão dos recursos orçamentários alocados no combate à criminalidade no País.

Nessa perspectiva, Santos, Gontijo e Amaral (2015) apontam que mesmo com a introdução da segurança no rol dos direitos dos cidadãos pela Carta de 1988, tal política não é considerada no âmbito da constituição como integrada no sistema de proteção social e não existem leis constitucionais vinculadas ao orçamento que assegurem um padrão mínimo de gastos ou investimentos neste setor. Cabe ressaltar que as políticas públicas na área da segurança são desenvolvidas pelo governo nas unidades federativas e buscam conter a criminalidade por ações preventivas ou de combate à violência (ARANTES et al., 2012).

Tal escalada da violência repercute de forma mais grave quando analisadas as peculiaridades regionais, como o caso do Nordeste e, particularmente, a Bahia, que figurou entre os estados nordestinos que aumentaram seus índices de homicídios entre 2005 e 2012 (DANTAS et al., 2016). Neste cenário, Pereira Filho, Tannuri-Pianto e Sousa (2010) pontuam que dado fenômeno da criminalidade, que se tornou um dos maiores problemas sociais brasileiro no período recente, exige-se além dos recursos financeiros, planejamento, inteligência operacional e coordenação nas diversas tentativas de combatê-la.

Essa discussão está presente na agenda dos governos, pesquisadores e da sociedade civil. Tais questionamentos são decorrentes do aumento da criminalidade que causam um custo social e impedem o desenvolvimento das atividades econômicas, como também uma redução na qualidade de vida advinda pelos danos morais e perdas de vidas induzidas pelo crime (LOBO; FERNANDEZ, 2003).

Segundo Odon (2018), o objetivo da sociedade é minimizar os danos causados pelo crime e, assim, buscar convencer, a um nível ótimo, os indivíduos de não cometerem crimes e isso depende da forma que os agentes e políticos alocam os recursos públicos. Neste aspecto, a avaliação da eficiência dos gastos públicos com segurança reveste-se de importância. Em outras palavras, trata-se de um indicador imprescindível que possibilita os gestores aplicarem os recursos 
públicos nesta área de forma ideal e proporcionar maior benefício à sociedade (SCHULL; FEITÓSA; HEIN, 2014).

Diante de sua relevância, esta questão tem sido amplamente discutida no contexto nacional (SCHULL, FEITÓSA e HEIN, 2014; LIMA et al., 2017; FREITAS JÚNIOR et al., 2020), estadual nordestino (DANTAS et al., 2016; NOGUEIRA et al., 2019) e municipal: Santa Catarina (SOARES, ZABOT e RIBEIRO, 2011); Minas Gerais (ARANTES et al., 2012; BOHN et al., 2015; ERVILHA et al., 2015). Observa-se que a Bahia, de forma desagregada, não foi contemplada neste rol.

Nesta perspectiva, esta pesquisa contribui favoravelmente para o estudo da temática em debate à luz da literatura especializada, à medida que aborda a segurança pública nos municípios baianos. Em primeiro lugar, o crescimento da criminalidade do estado não se restringe apenas às grandes regiões. A este respeito, Moreira e Fochezatto (2017) argumentam que existe um mecanismo de transbordamento e transferência da atividade criminosa, isto é, a criminalidade de um município é afetada pelas regiões vizinhas.

Ademais, Soares (2014) aponta que os altos índices de criminalidade, especialmente juvenil, na Bahia é resultado da ineficiência das políticas de segurança pública em conter a violência e criminalidade que se tornam um fenômeno complexo ao associar com outros fatores, como desemprego e ausência de políticas que promovam a igualdade e inclusão social. Araújo (2016) mostra um crescimento das despesas com segurança pública na Bahia entre 2011 e 2014, sendo que, no ranking dos dez estados mais populosos, foi o quinto que mais investiu nesta função. Ao mesmo tempo, o estado foi o mais violento durante o período, em termos absolutos. Tais colocações justificam a necessidade de estudos que busquem aferir a qualidade dos gastos públicos na promoção da segurança nos municípios baianos.

Posto isto, o objetivo deste trabalho consiste em analisar a eficiência dos gastos públicos municipais com segurança na Bahia. Para tal, foram calculadas as fronteiras de eficiência dos municípios baianos para os modelos de eficiência técnica e de escala, bem como especificados os tipos de rendimentos de escala considerando as estatísticas criminais e os gastos na função segurança em 2018.

Além dessa seção introdutória, o artigo é constituído por quatro seções. A segunda se dedica à revisão bibliográfica que compreende o embasamento sobre a teoria econômica do crime e a revisão de literatura nacional dos estudos que investigaram a eficiência dos recursos públicos destinados à segurança. Os procedimentos metodológicos são mostrados na terceira, seguido pela apresentação e discussão dos resultados, enquanto a última seção é destinada às considerações finais. 


\section{Revisão bibliográfica}

\section{Fundamentos teóricos da economia do crime}

A discussão e a preocupação em definir, prevenir e combater o crime não são recentes na história da sociedade, ao contrário, remotam os primórdios da evolução humana (SHIKIDA, 2005). Contudo, segundo Bohn et al. (2015) e Ervilha et al. (2015), desde o século XVIII, propõese justificativas para explicar este fenômeno, seja associando as causas da criminalidade ao indivíduo ou à sociedade, seja por correntes biológicas e psicológicas ou ainda, como resposta do homem ao meio em que reside. Neste particular, busca-se discorrer acerca da criminalidade como objeto de estudo das Ciências Econômicas.

Dessa forma, a teoria econômica disserta que os indivíduos agem de forma racional e ponderada e, portanto, respondem aos incentivos mediante uma relação de custo e benefício atrelado às suas escolhas. Nestes termos, em um contexto em que o agente não consegue atingir seus objetivos, devido a sua restrição orçamentária no setor legal econômico, ele busca mensurar os benefícios e os custos oriundos caso aplicasse seu tempo e trabalho em um setor ilegal, sendo esta, uma decisão semelhante a escolha de uma ocupação de um posto de trabalho (SOARES; ZABOT; RIBEIRO, 2011). Esta análise advém da Teoria Econômica do Crime, formulada por Becker (1968).

Em 1992, Gary Becker recebeu o Prêmio de Ciências Econômicas em Memória de Alfred Nobel, por sua explicação do comportamento criminal utilizando uma modelagem focada na escolha individual sob incerteza (SANTOS; CASAGRANDE; HOECKEL, 2015). Segundo Santos e Kassouf (2008), a estrutura do modelo é assentada na hipótese de racionalidade do potencial criminoso em que se propõe que, agindo racionalmente, um indivíduo cometerá um delito se e somente se a utilidade esperada por ele for superior à utilidade obtida se este empregasse seu tempo e recursos em uma atividade lícita. Assim, para Becker (1968), o crime é uma atividade econômica, apesar de ilegal, e o criminoso, um "empresário".

Dito de outra forma, em termos de marginalização econômica, esta teoria é pautada nas noções de sujeito econômico representativo, isto é, um sujeito racional, movido pela escolha e pela tomada de decisões. Estes elementos colocam o indivíduo em uma situação de maximização do seu prazer e minimização do seu sofrimento e, neste caso, a criminalidade está associada às oportunidades. Além disso, todas as pessoas são criminosas em potencial, já que sua ação (criminosa ou não) resulta da otimização de sua função utilidade, que leva em conta o retorno entre o mercado lícito e o mundo do crime (BOHN et al., 2015).

Segundo Shikida (2005), assim como em uma atividade econômica qualquer, os ganhos obtidos com a atividade empresarial do crime são incertos e dependem da probabilidade de 
sucesso em suas operações e, por um lado, é diretamente correlacionada com o desempenho do criminoso e, por outro, à eficácia do sistema policial e eficiência da justiça. Para Becker (1968), uma menor probabilidade de o indivíduo ser capturado associado a uma reduzida punição, implica uma elevada probabilidade de um criminoso vir a cometer um delito.

Estas duas variáveis são as mais importantes, entre as que Becker (1968) equacionou em seu modelo. Odon (2018) concorda com tal colocação e assinala que tais variáveis são relevantes para a opção pelo crime e a escolha de qual delito será cometido. Ademais, segundo Odon (2018), o trabalho de Ehrlich (1973) testou empiricamente o modelo de Becker (1968) e concluiu que sejam crimes contra o patrimônio ou contra a pessoa, o comportamento criminoso é sensível à variação da probabilidade de sua detenção e a severidade da punição, se for detido.

Kelly (2000), todavia, argumenta que delitos contra a propriedade podem ser explicados em maior grau pela teoria econômica do crime, ao passo que crimes contra a pessoa são melhores explicados pela teoria de desorganização social. Esta última teoria encontra respaldo em Cerqueira e Lobão (2003), que os definem como uma abordagem sistêmica, em que o enfoque se dá em torno das comunidades locais que são entendidas como um complexo sistema de redes formais e informais, de relações de amizades, parentescos e demais formas que contribuem para o processo de socialização do indivíduo.

Além da teoria proposta por Becker (1968), considerada o estado da arte em economia do crime, existem outras concepções nas Ciências Econômicas que buscam explicar a criminalidade. Nessa perspectiva, Dantas et al. (2016) apontam uma teoria de origem marxista cuja argumentação advoga que aumentos da criminalidade, especialmente delitos lucrativos, estão relacionados com as características do processo capitalista; e uma corrente que relaciona o aumento da criminalidade com problemas estruturais e conjunturais, como desemprego e concentração de renda. Lobo e Fernandez (2003) também consideram estas correntes no debate sobre economia e criminalidade e salientam que altos índices de desempregos, concentração de renda, baixos níveis de escolaridade e de renda podem agravar este problema.

Tais postulados fundamentam diversos estudos na economia do crime, bem como nas discussões que envolvem o combate da criminalidade e a utilização eficiente dos recursos alocados nessa função. Sendo assim, na próxima subseção, serão discutidos os principais estudos da literatura nacional que empregaram a Análise Envoltória de Dados, do inglês Data Envelopment Analysis (DEA), para análise de eficiência dos gastos públicos com segurança nos últimos dez anos. 


\section{Evidências empíricas, da abordagem DEA, em economia do crime}

Soares, Zabot e Ribeiro (2011), a priori, construíram um índice de criminalidade mediante a técnica de análise fatorial e, em seguida, criaram uma fronteira relativa de eficiência para 18 municípios representativos das mesorregiões catarinenses, considerando o ano de 2003. Os resultados permitiram inferir que a maioria dos municípios eficientes apresentou menores indicadores de criminalidade.

Ainda no âmbito estadual, Arantes et al. (2012) avaliaram a eficiência de 316 municípios mineiros no que concerne à alocação dos recursos destinados à segurança pública para 2007. Verificaram que, da amostra de municípios analisados, 18 se mostraram eficientes no modelo com retornos variáveis de escala (VRS), enquanto, no modelo com retornos constantes (CRS), apenas dois (Monte Azul e Peçanha) foram plenamente eficientes. Ademais, constataram que furtos, roubos e homicídios tiveram maiores médias para os municípios considerados.

Utilizando dados do Anuário de Segurança Pública, Schull, Feitósa e Hein (2014) mediram a eficiência de 23 estados brasileiros na alocação dos gastos públicos com segurança, em 2011, e demonstraram que 12 desses apresentaram máximo escore de eficiência, dois tiveram nível alto e os demais responderam com grau médio para o modelo VRS, sendo que Tocantins foi o que apresentou menor índice de eficiência. Além disso, identificaram o alvo a ser atingido para que os estados ineficientes alcançassem o nível máximo de eficiência, sendo que a Paraíba apresentou o menor alvo a ser atingido.

Bohn et al. (2015) procederam a análise de eficiência para 752 municípios de Minas Gerais e identificaram os determinantes socioeconômicos para o período de 2000 a 2010. Os autores refinaram os resultados obtidos por meio da detecção de outliers, método de restrição aos pesos e teste não-paramétrico U de Mann-Whitney para fronteira de eficiência, em que a amostra foi dividida em três estratos da população. Em seguida, empregaram o modelo de regressão Tobit visando explicar a influência de variáveis não-discricionárias sobre a alocação dos recursos destinados à segurança pública. Os resultados permitiram inferir que a urbanização e a qualidade da educação impactam na eficiência dos três grupos populacionais, apresentando, respectivamente, relação positiva e negativa com a ineficiência e que, os municípios com menor população, Índice de Gini e PIB per capita, registraram relação positiva com a ineficiência.

Os municípios mineiros também foram objetos de estudo de Ervilha et al. (2015). Os resultados foram refinados pelo método de restrição aos pesos e pela detecção de outliers. Ademais, os autores analisaram os índices em termos de espacialidade do território. Os resultados revelaram baixo índice de eficiência, sendo que os municípios ao norte e ao sul se mostraram 
mais eficientes, sinalizando a presença de clusters de eficiência, ao passo que os menos eficientes se concentraram nas regiões oeste e leste.

Dantas et al. (2016) estimaram a eficiência dos gastos públicos com segurança para os estados nordestinos, em 2013, e consideraram o método de supereficiência na identificação dos outliers. Com base neste método, a Paraíba foi considerada como outliers, portanto, foi eliminado do cálculo das estimações de eficiência. O estudo mostrou que 37,5\% dos estados considerados da região Nordeste situam-se sobre a fronteira de eficiência. Isso significa dizer que os estados nordestinos são, em sua maioria, ineficientes nos gastos em segurança pública.

A análise da eficiência na alocação dos gastos públicos com segurança também foi objeto de estudo de Lima et al. (2017) para 23 estados brasileiros em 2015. Dentre esses estados, dez deles atingiram o nível máximo de eficiência, sete obtiveram alto grau de eficiência e seis foram classificados com médio grau de eficiência.

Nogueira et al. (2019) investigaram a eficiência dos gastos públicos com segurança no Nordeste brasileiro de 2008 a 2012. Para tal, colheram dados do Anuário Brasileiro de Segurança Pública e da plataforma Finanças Brasil. Os resultados revelaram elevado grau de ineficiência na gestão dos recursos públicos na área de segurança. Verificaram também que, apesar do aumento significante dos gastos nesta área, durante o período analisado, houve elevação expressiva nos indicadores de criminalidade dos estados do Nordeste.

Freitas Júnior et al. (2020) buscaram identificar os fatores que influenciaram o desempenho dos gastos com segurança pública em 23 estados brasileiros, no período de 2011 a 2015. Dentre tais estados, a Paraíba se destacou com o melhor desempenho na segurança pública do país, ao passo que Rondônia teve o pior desempenho. Os resultados mostraram também que estados com maior efetivo policial, maiores receitas próprias e maior quantitativo populacional tendem a conquistar melhores níveis de eficiência.

Dentre os trabalhos citados nessa revisão de literatura, o estado da Bahia foi objeto de estudo de Schull, Feitósa e Hein (2014); Dantas et al. (2016); Lima et al. (2017); Nogueira et al. (2019); e Freitas Júnior et al. (2020), porém nenhum desses analisou a eficiência dos gastos públicos municipais com segurança na Bahia. Neste sentido, ratifica-se que este estudo preenche esta lacuna.

\section{Metodologia}

A Análise Envoltória de Dados (Data Envelopment Analysis, em inglês - DEA) consiste em uma abordagem não paramétrica, para a mensuração da eficiência relativa de firmas com múltiplos insumos e múltiplos produtos (BOHN et al., 2015). Em conformidade com Arantes et 
al. (2012), esta modelagem considera cada unidade produtora e as dominam de Unidades Tomadoras de Decisão (Decision Making Unit, em inglês - DMU). Na prática, é determinada a eficiência de uma unidade produtiva em termos comparativos com as demais. Além disso, de acordo com Bohn et al. (2015), para as unidades consideradas ineficientes, o DEA fornece seu respectivo benchmark, ou seja, DMUs de referências que consistem na projeção de tais unidades na fronteira de eficiência.

O método DEA, cuja fundamentação deriva dos trabalhos de Farrel (1957) e Charnes, Cooper e Rhodes (1978), pode ser apresentado em dois modelos considerados clássicos, a saber: Retornos Constantes de Escala (Constant Returns to Scale - CRS ou CCR) e Retornos Variáveis de Escala (V ariable Returns to Scale - VRS ou BCC) (DANTAS et al., 2016).

De acordo com Rebelo, Matias e Carrasco (2013), o modelo CRS ou CCR (proposto por Charnes, Cooper e Rhodes) analisa a eficiência produtiva de uma unidade, identifica as fontes de ineficiências e estima o montante desta ineficiência. Ademais, reitera-se que o CRS trabalha com retornos constantes de escala, ou seja, uma variação nas entradas (inputs) implica uma variação proporcional nas saídas (outputs), sendo ignorado o efeito da escala neste tipo de análise, o que é contornado pelo VRS.

Por seu turno, o modelo VRS foi desenvolvido por Banker, Charnes e Cooper (1984), sendo uma extensão do estudo de Charnes, Cooper e Rhodes (1978). A mudança entre os dois é que o VRS utiliza retornos variáveis de escala. Além disso, tal retorno substitui o axioma da proporcionalidade entre os imputs e outputs pela convexidade, isto é, pressupõe que a fronteira de produção seja convexa, o que permite que DMUs que operam com baixos valores de insumos tenham retornos crescentes de escala, e as que operam com níveis alto apresentem retornos decrescentes de escala (BOHN et al., 2015; DANTAS et al., 2016).

As equações (1) e (2), respectivamente, representam os modelos DEA com retornos constantes e variáveis de escala considerando a orientação produto (COELLI; RAO; BATTESE, 1998).

$$
\begin{aligned}
& \operatorname{Max}_{\theta, \lambda} \theta \text {, sujeito } a:-\theta y_{i}+Y \lambda>0, x_{i}-X \lambda \geq 0 \text { e } \lambda \geq 0 \\
& \operatorname{Max}_{\theta, \lambda} \theta \text {, sujeito } a:-\theta y_{i}+Y \lambda>0, x_{i}-X \lambda \geq 0, N_{1}^{\prime} \lambda=1 \text { e } \lambda \geq 0 \text { (2) }
\end{aligned}
$$

Em que: $1 \leq \theta<\infty$ corresponde ao escore de eficiência técnica bruto das DMUs; $(\theta-1)$ diz respeito à elevação proporcional do produto que poderia ser adquirida pela i-ésima DMU, mantendo-se constante o uso dos insumos. Por meio da expressão $(\bar{\theta}-1)$, pode-se obter o montante médio da eficiência técnica das DMUs, sendo que $\bar{\theta}$ se refere à média de $\theta$; ao passo que $1 / \theta$ representa o escore de eficiência padronizado de uma unidade tomadora de decisão, 
com variação de zero a um; $y$ por seu turno, associa-se ao produto da DMU e $x$ simboliza o insumo; $X$ representa a matriz de insumos $(n x k)$ e $Y$ equivale a matriz de produtos $(n x m) ; \lambda$ apresenta-se como vetor de constantes que multiplica a matriz de insumos e produtos; $N_{1}$ representa o vetor $(N x 1)$ de algarismos unitários.

\section{Deteç̧ão de outliers e Teste U de Mann-Whitney}

Segundo Pereira Filho, Tannuri-Pianto e Sousa (2010), o DEA possui a vantagem de não necessitar da imposição de uma forma funcional para as variáveis, mas apresenta resultados mais suscetíveis às perturbações estocásticas, especialmente à presença de outliers, já que não possui tratamento para o termo de erro. Neste sentido, a literatura recomenda a identificação e a remoção dos outliers para não comprometer os resultados.

Para identificação dos outliers, Bohn et al. (2015) e Ervilha et al. (2015) seguiram o método "jackstrap", também empregado neste estudo. Tal procedimento, proposto por Sousa, CribariNeto e Stosic (2005), corresponde à combinação de dois métodos de reamostragem: jackkknife (determinístico) e bootstrap (estocástico). Neste processo, conforme Ervilha et al. (2015), em primeiro momento, utiliza-se o jackknife para computar a influência de cada DMU na mensuração da eficiência; em um segundo momento, se emprega o bootstrap de amostragem estocástica, sendo nesta etapa, considerada a informação das influências obtidas na anterior.

De acordo com Rodrigues, Brito e Sousa (2018), este procedimento consiste em construir uma medida de leverage com o intuito de mensurar a influência de cada DMU sobre as demais, e aqueles que apresentarem maiores influências devem ser removidas da análise para não comprometer as estimações do DEA. Ademais, em termos algébricos, o leverage pode ser definido como o desvio padrão das medidas de eficiência antes e depois da remoção de cada DMU da amostra (SOUSA; CRIBARI-NETO; STOSIC, 2005).

Além disso, Bohn et al. (2015) ressaltam que os resultados produzidos pelo DEA são sensíveis aos erros de medidas, especificações de fatores e ao tamanho do grupo que está sendo analisado. Assim, tais autores esclarecem que a comparação de indicadores de eficiência entre unidades muito díspares pode ocasionar conclusões errôneas, como, por exemplo, comparar os índices de eficiência de municípios com cinco mil habitantes com os de metrópoles. Dessa forma, recomenda-se que sejam verificados se municípios, mesmo com tamanhos diferentes, pertencem a uma mesma fronteira de eficiência ou se cada estrato apresenta sua própria fronteira (ERVILHA et al., 2015). Para tal, aplicou-se o teste U de Mann-Whitney. 
Segundo Firmino (2015), o teste não paramétrico U de Mann-Whitney é utilizado para verificar se dois grupos de variáveis aleatórias interdependentes foram ou não extraídos da mesma população. Para realização deste teste, a amostra de municípios baianos foi dividida em três estratos populacionais, a saber: até 20 mil habitantes, entre 20 mil até 100 mil habitantes e com mais de 100 mil habitantes.

\section{Fontes dos dados e seleção da amostra}

A operacionalização do método DEA requer dados de insumos e produtos. No que tange aos insumos, foram utilizados os gastos públicos com segurança per capita dos municípios baianos obtidos juntos ao Sistema de Informações Contábeis e Fiscais do Setor Público Brasileiro (SICONFI, 2020), do Tesouro Nacional. De acordo com essa base de dados, dos 417 municípios pertencentes ao estado da Bahia, 148 deles declararam despesas por função Segurança Pública em 2018. No que diz respeito aos produtos, adotaram-se as taxas de criminalidade (homicídios dolosos; estupro; e roubo e furto de veículos) ponderadas pela população do respectivo município. Para tal, inspirado no índice utilizado por Barbosa e Sousa (2012) para o Ceará, representado pela equação (3), adaptou-se para os municípios baianos.

$I B_{i}=\frac{100.000 E}{p}(3)$

Em que: $I B_{i}$ corresponde ao índice bruto de cada variável i; $E$ representa o número de eventos ocorridos e $P$ a população do município.

Dessa forma, foram construídos os seguintes indicadores: Índice Bruto de Homicídio Doloso (IBHD), Índice Bruto de Estupro (IBE) e Índice Bruto de Roubo e Furto de Veículo (IBRFV). As estatísticas criminais requeridas para o cômputo destes índices foram provenientes da Secretaria de Segurança Pública da Bahia (SSP, 2020). A escolha desses indicadores criminais foi baseada em um maior número de municípios com dados disponíveis diferentes de zero, para viabilizar o cálculo dos escores de eficiência. Dos 148 municípios que declararam despesas por função Segurança Pública em 2018, 114 registraram ocorrências de homicídios dolosos; 122 de estupros; e 123 de roubo e furto de veículos. Dessa amostra de municípios, foram selecionados 95 municípios baianos que tiveram dados simultâneos para os insumos e produtos considerados neste estudo.

Seguindo a pesquisa de Dantas et al. (2016), este estudo adotou a orientação do produto, em que se busca maximizar os produtos sem aumentar os insumos. Dada esta escolha, foram considerados os inversos dos índices brutos de criminalidade. Este procedimento foi inspirado na metodologia de Nogueira et al. (2019). 


\section{Análise e discussão dos resultados}

Tendo em vista que o método DEA é muito sensível à presença de outliers, estudos, como de Bohn et al. (2015) e Ervilha et al. (2015), identificaram os municípios considerados como outliers e excluíram da análise para não comprometer os resultados. Seguindo o procedimento empregado em tais estudos e especificado na metodologia, constatou-se que o ponto de corte adotado é 0,0456. Assim, verificou-se que, da amostra de 95 municípios baianos, 13 deles tiveram valores acima desse ponto de corte, sendo, portanto, desconsiderados deste estudo. Além da capital baiana, que faz parte da Região Metropolitana de Salvador, tem-se outro município localizado nesta mesorregião (São Sebastião do Passé); dois no Nordeste baiano (Paripiranga e Adustina); quatro no Centro-Sul baiano (Ibipitanga, Ubaíra, Pindaí e Riacho de Santana); dois no Extremo-Oeste baiano (Lapão e Valente), dois no Centro-Norte baiano (Água Fria e Coração de Maria) e um no Vale São-Franciscano baiano (Ibotirama).

Após a exclusão desses municípios indicados como outliers, conforme descrito nos procedimentos metodológicos, realizou-se o teste não paramétrico $U$ de Mann-Whitney para verificar se existem diferenças entre as fronteiras de eficiência dos municípios desagregados por grupos populacionais. Como se observa pela Tabela 1, a amostra de municípios considerados foi dividida em três grupos populacionais: até 20 mil habitantes, entre 20 mil até 100 mil habitantes e com mais de 100 mil habitantes. Os resultados deste teste indicam que não se rejeita a hipótese nula, em que os grupos analisados fazem parte da mesma população nas três comparações efetuadas (1 e 2; 1 e 3; e 2 e 3). Isso significa dizer que não é necessário proceder a análise das fronteiras dos grupos considerados de forma separada, ou seja, o tamanho dos municípios em questão não influencia os escores aferidos de eficiência no modelo VRS.

Tabela 1 - Valores do teste de Mann-Whitney para os grupos desagregados em termos populacionais

\begin{tabular}{ccccc}
\hline $\begin{array}{c}\text { Grupos } \\
\text { populacionais* }\end{array}$ & $\begin{array}{c}\text { U de Mann- } \\
\text { Whitney }\end{array}$ & W de Wilcoxon & Z & Significância \\
\hline 1 e 2 & 566.000 & 1.556 .000 & $-0,83$ & 0,41 \\
1 e 3 & 104.000 & 539.000 & $-0,94$ & 0,35 \\
2 e 3 & 130.500 & 1.120 .500 & $-1,62$ & 0,11 \\
\hline
\end{tabular}

Fonte: elaborada pelos autores

Nota: * Grupo 1: municípios com até 20 mil habitantes; Grupo 2: municípios entre 20 mil até 100 mil habitantes; Grupo 3: municípios com mais de 100 mil habitantes. 
A Tabela 2 exibe as principais estatísticas descritivas das variáveis relativas aos inversos dos índices brutos de criminalidades e aos gastos públicos per capita com segurança empregados para estimar a fronteira de eficiência. Quanto aos outputs, percebe-se que o inverso do índice bruto de roubo e furto de veículo (1/IBRFV) foi o que se destacou com maior heterogeneidade, captada pelo alto coeficiente de variação, e maior valor máximo. Dentre a amostra de municípios baianos considerados neste estudo, Ibicaraí, que faz parte da mesorregião Sul baiano, obteve o maior valor, ao passo que Lauro de Freitas, sediado na Região Metropolitana de Salvador, registrou o menor valor para essa variável. Isso indica que Lauro de Freitas liderou o ranking com o pior índice bruto de roubo e furto de veículo, em 2018, com uma taxa per capita de 307,23 por 100 mil habitantes. Segundo Moreira e Fochezatto (2017), em 2014, Lauro de Freitas já figurava entre os dez municípios mais violentos da Bahia.

Tabela 2 - Estatísticas descritivas das variáveis consideradas na aferição dos escores de eficiência dos gastos com segurança pública nos municípios baianos, 2018

\begin{tabular}{lccccc}
\hline Variáveis & Mínimo & Média & Máximo & Desvio padrão & CV (\%) \\
\hline 1/IBHD & 0,01 & 0,05 & 0,19 & 0,04 & 77,49 \\
1/IBE & 0,02 & 0,06 & 0,18 & 0,04 & 64,38 \\
1/IBRFV & 0,00 & 0,03 & 0,24 & 0,03 & 118,32 \\
Gastos com segurança/hab. & 0,02 & 12,92 & 101,52 & 20,57 & 159,17 \\
\hline
\end{tabular}

Fonte: elaborada pelos autores

No tocante ao inverso do índice bruto de estupro (1/IBE), Cachoeira, que faz parte da Região Metropolitana de Salvador, e Planaltino, sediado na mesorregião Centro-Sul baiano, tiveram, respectivamente, os valores mais alto e baixo para tal variável. Em outros termos, o município de Planaltino registrou o índice bruto de estupro mais insatisfatório, em 2018, com uma taxa per capita de 62,97 por 100 mil habitantes, estando muito acima da média obtida pelo estado da Bahia, em 2011, que foi de 12,7 por 100 mil habitantes, segundo Schull, Feitósa e Hein (2014); e, em 2015, que foi de 16 por 100 mil habitantes, conforme Lima et al. (2017). Em termos médios, porém, nota-se pela Tabela 2 que a amostra de municípios baianos analisados foi de 0,06 para a variável $1 / \mathrm{IBE}$, ficando abaixo da média obtida pelos estados brasileiros, que foi de 0,85 , no período de 2011 a 2015, consoante Freitas Júnior et al. (2020).

Em relação ao inverso do índice bruto de homicídio doloso (1/IBHD), os municípios de Cocos, pertencente ao Extremo-Oeste baiano, e Amélia Rodrigues, localizado na Região Metropolitana de Salvador, destacaram-se, respectivamente, com o maior e o menor valor para essa variável. Portanto, pode-se dizer que Amélia Rodrigues liderou o ranking com o pior índice bruto de homicídio doloso, em 2018, com uma taxa per capita de 83,26 por 100 mil habitantes. Ao comparar esse resultado com os obtidos para o estado da Bahia nos estudos realizados por 
Schull, Feitósa e Hein (2014) e Lima et al. (2017), tem-se, respectivamente, os valores de 31,1, em 2011, e 37,5, em 2015, logo, percebe-se que esse índice está piorando ao longo do tempo. Entretanto, a média obtida para a amostra de municípios baianos considerados neste estudo foi de 0,05 (Tabela 2) para a variável 1/IBHD, enquanto Freitas Júnior et al. (2020) encontraram uma média de 0,98 para os estados brasileiros, no período de 2011 a 2015.

No que diz respeito ao input, representado neste estudo pelos gastos públicos per capita com segurança, tem-se que, dentre a amostra investigada, o município de Itaberaba, que faz parte do Centro-Norte baiano, gastou somente $\mathrm{R} \$ 0,02$ por habitante, em 2018. Em contrapartida, o município de Luís Eduardo Magalhães, sediado no Extremo Oeste baiano, foi o que registrou o maior gasto público com segurança no valor de $\mathrm{R} \$ 101,52$ por habitante, em 2018. Apesar de ter sido o município baiano que mais gastou com segurança pública, o município de Luís Eduardo Magalhães ficou bastante aquém dos gastos auferidos para o estado da Bahia, em 2011, que foi de $\mathrm{R} \$ 183,13$ por habitante (SCHULL; FEITÓSA; HEIN, 2014), e, em 2015, que foi de $\mathrm{R} \$ 244,52$ por habitante (LIMA et al., 2017). Para Freitas Júnior et al. (2020), a média dessa variável para os estados brasileiros, no período de 2011 a 2015, foi de $\mathrm{R} \$ 306,34$ por habitante.

As estatísticas descritivas dos escores de eficiência padronizado (E) dos índices brutos de criminalidade e o acréscimo proporcional nos produtos que um dado município pode obter sem alterar os gastos públicos municipais com segurança estão mostradas na Tabela 3.

Tabela 3 - Estatísticas descritivas dos escores de eficiência técnica com retornos constantes à escala (CRS), retornos variáveis à escala (VRS) e eficiência de escala dos gastos com segurança pública nos municípios baianos, 2018

\begin{tabular}{|c|c|c|c|c|c|c|}
\hline \multirow{3}{*}{$\begin{array}{l}\text { Estatísticas descritivas de } \\
\qquad E=1 / \theta \text { e } \theta-1^{*}\end{array}$} & \multicolumn{4}{|c|}{ Eficiência técnica } & \multirow{2}{*}{\multicolumn{2}{|c|}{ Eficiência de escala }} \\
\hline & \multicolumn{2}{|c|}{ CRS } & \multicolumn{2}{|c|}{ VRS } & & \\
\hline & $\mathrm{E}$ & $\theta-1$ & $\mathrm{E}$ & $\theta-1$ & $\mathrm{E}$ & $\theta-1$ \\
\hline Mínimo & 0,00 & 0,00 & 0,15 & 0,00 & 0,00 & 0,00 \\
\hline Máximo & 1,00 & 999,00 & 1,00 & 5,90 & 1,00 & 999,00 \\
\hline Média & 0,07 & 223,23 & 0,64 & 1,07 & 0,08 & 109,69 \\
\hline Desvio padrão & 0,16 & 331,75 & 0,28 & 1,32 & 0,16 & 169,31 \\
\hline CV $(\%)$ & 238,05 & 148,61 & 43,81 & 123,54 & 201,56 & 154,35 \\
\hline
\end{tabular}

Fonte: elaborada pelos autores

Nota: ${ }^{*} E=1 / \theta$ representa o escore de eficiência padronizado de uma DMU e $\theta-1$ corresponde o acréscimo proporcional nos produtos considerados neste estudo, isto é, no inverso dos índices brutos de criminalidade, que pode ser obtido pela i-ésima DMU, mantendo-se o uso dos insumos inalterados.

O escore de eficiência padronizado com retornos variáveis à escala (VRS) registrou a maior média observada $(0,64)$, porém obteve o mais baixo coeficiente de variação $(43,81 \%)$. Em contrapartida, o escore de eficiência técnica com retornos constantes à escala (CRS) auferiu a menor média observada $(0,07)$, mas com a maior heterogeneidade, traduzida pelo coeficiente de 
variação $(238,05 \%)$ da amostra. Assim, pode-se inferir que, em termos médios, a ineficiência técnica dos gastos com segurança pública para os municípios baianos é de, respectivamente, $93 \%$ e $36 \%$, para os modelos CRS e VRS. Esse resultado considerando a pressuposição de retornos variáveis à escala foi corroborado por Schull, Feitósa e Hein (2014) para o estado da Bahia. Em relação à ineficiência de escala, nota-se que é de $92 \%$, indicando que parcela majoritária da amostra de municípios baianos analisados está aplicando o insumo de modo indevido. Os dados da Tabela 3 também revelam que, em média, os produtos considerados podem aumentar sem modificar o uso dos insumos.

A Tabela 4 expõe os resultados dos escores de eficiência técnica (CRS e VRS) e de escala dos municípios baianos por estratos de eficiência dos gastos públicos com segurança, sob a orientação produto. Para Schull, Feitósa e Hein (2014), municípios com escores de eficiência até 0,25 apresentam baixo grau de eficiência; de 0,26 a 0,74 possuem médio grau de eficiência; de 0,75 a 0,99, alto grau de eficiência; e 1,0 indica o máximo nível de eficiência alcançado. Seguindo esse critério de classificação, tem-se que 93,90 \% e 92,68 \% dos municípios baianos, respectivamente, nos modelos de eficiência técnica sob a pressuposição de retornos constantes à escala e de eficiência de escala, estão obtendo baixa eficiência quanto aos gastos públicos com segurança. No que concerne ao modelo com retornos variáveis à escala, os dados sinalizam que $58,54 \%$ dos municípios baianos apresentam médio grau de eficiência.

Tabela 4 - Distribuições de frequências absolutas e relativas dos gastos públicos com segurança nos municípios baianos considerados por estratos de eficiência técnica (CRS e VRS) e de escala, 2018

\begin{tabular}{|c|c|c|c|c|c|c|}
\hline \multirow{3}{*}{ Estratos de eficiência } & \multicolumn{4}{|c|}{ Eficiência técnica } & \multirow{2}{*}{\multicolumn{2}{|c|}{ Eficiência de escala }} \\
\hline & \multicolumn{2}{|c|}{ CRS } & \multicolumn{2}{|c|}{ VRS } & & \\
\hline & fi & $\%$ & $\mathrm{fi}$ & $\%$ & fi & $\%$ \\
\hline$E<0,25$ & 77 & 93,90 & 5 & 6,10 & 76 & 92,68 \\
\hline $0,25 \leq E<0,5$ & 1 & 1,22 & 24 & 29,27 & 2 & 2,44 \\
\hline $0,5 \leq E<0,75$ & 3 & 3,66 & 24 & 29,27 & 3 & 3,66 \\
\hline $0,75 \leq E<1,0$ & 0 & 0,00 & 9 & 10,98 & 0 & 0,00 \\
\hline$E=1,0$ & 1 & 1,22 & 20 & 24,39 & 1 & 1,22 \\
\hline Total & 82 & 100,00 & 82 & 100,00 & 82 & 100,00 \\
\hline
\end{tabular}

Fonte: elaborada pelos autores

A partir de tais dados, constata-se que, dos 82 municípios baianos analisados neste estudo, somente Itaberaba, localizado no Centro-Norte baiano, atingiu o máximo grau de eficiência técnica, no modelo CRS, mesmo tendo sido o município que menos gastou com segurança pública ( $\mathrm{R} \$ 0,02$ por habitante) em 2018. Por outro lado, parcela majoritária (93,90\%) dos municípios estudados tiveram escores de eficiência abaixo de 0,25 nesse modelo, sendo que 
os escores de eficiência de 11 de tais municípios foram de apenas 0,001. Dentre eles, encontra-se Luís Eduardo Magalhães, que foi o município que mais destinou recursos para a segurança pública por habitante, em 2018. Esse resultado indica que não necessariamente os maiores dispêndios realizados com segurança pública promovem melhores níveis de eficiência, que é o que ocorre nos estados de Alagoas e Sergipe no estudo de Dantas et al. (2016).

Ao se incorporar uma restrição de convexidade, verifica-se que 19 municípios a mais (Santa Inês, Cocos, Biritinga, Teofilândia, Camacan, Jacobina, São Gonçalo dos Campos, Mirangaba, Jacaraci, Coribe, Mulungu do Morro, Iaçu, Brumado, Itiruçu, Ibicaraí, Candiba, Cachoeira, Santa Brígida e Riachão das Neves) do que no modelo CRS estão na fronteira de retornos variáveis à escala, mas não fazem parte da fronteira de retornos constantes. Isso revela que tais municípios não possuem problemas quanto ao uso excessivo de insumos, porém detêm problemas concernentes à escala empregada de forma indevida. No tocante à eficiência de escala, constata-se que a maioria dos municípios avaliados (92,68 \%) apresentou ineficiência de escala, uma vez que tiveram escores de eficiência de escala abaixo da unidade, podendo ser atribuídos à presença de retornos decrescentes de escala, ou seja, o acréscimo da produção ocorre em virtude dos custos médios crescentes. A Figura 1 indica a localização dos municípios baianos analisados e o estrato de eficiência a que pertence.

Figura 1 - Distribuições dos municípios baianos considerados por estratos de eficiência técnica (CRS e VRS) e de escala, 2018
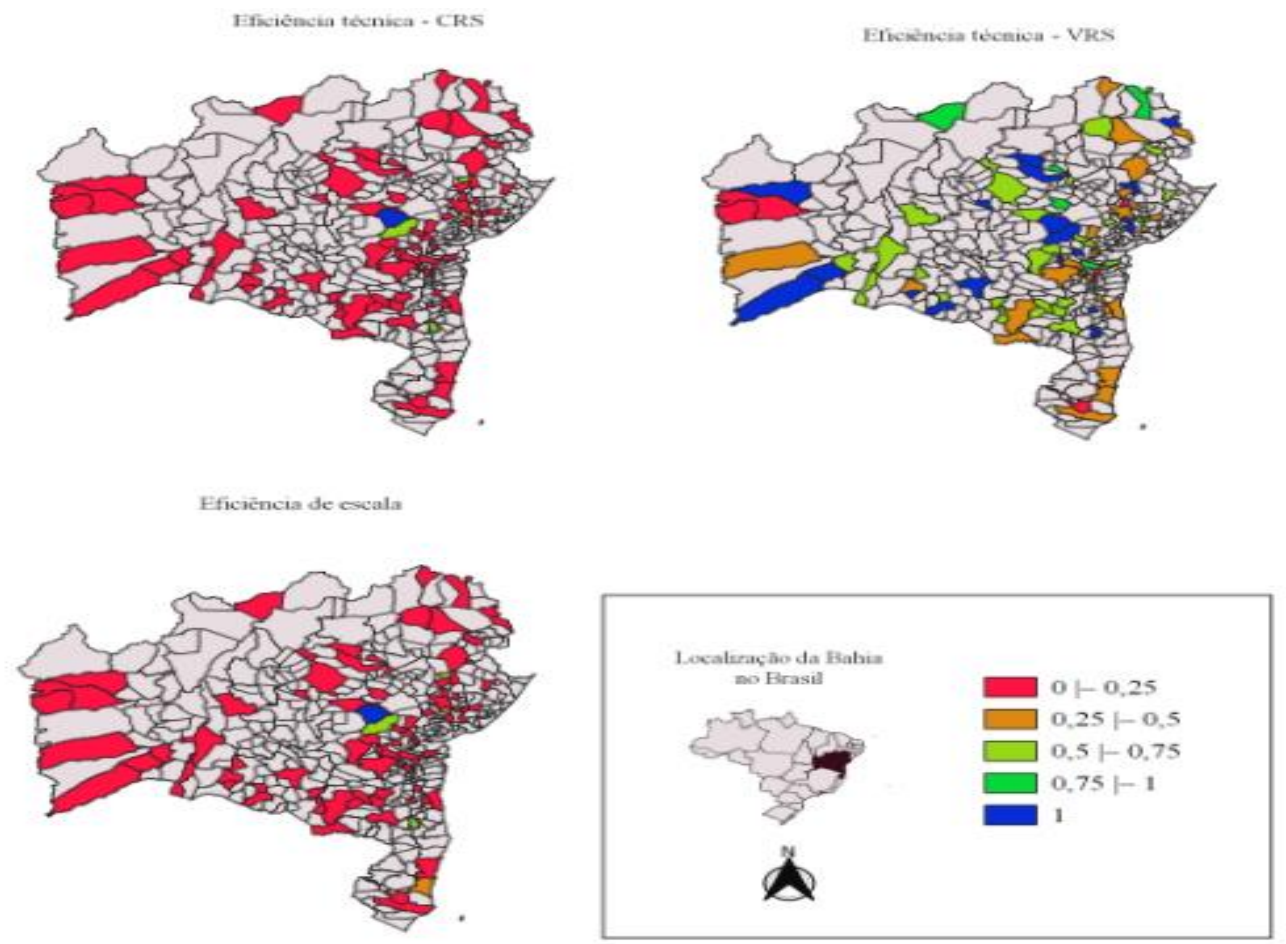

Fonte: elaborada pelos autores 
Os resultados apresentados sinalizam que a criminalidade não tem se restringido somente as grandes regiões e que a ineficiência não está heterogeneamente distribuída no território analisado. Nielsen (2009) pondera que a violência no Brasil se deslocou para o interior do país, deixando de ser uma característica das capitais e grandes metrópoles, atingindo cidades menores e fronteiras. Não diferente dos outros estados, a Bahia tem experimentado crescimento da violência, desde o início do século XXI. A este respeito, Soares (2014) ressalta que as expressivas taxas de homicídios na Bahia, a partir de 2001, relacionam-se a diversos fatores, como, por exemplo: a) ausências de políticas que possibilitam a ampliação do acesso dos jovens ao mercado de trabalho e b) falta de investimentos eficazes por parte da Secretaria de Segurança Pública para o combate da criminalidade, o que compromete o desempenho da polícia militar do estado, que chegou a realizar greves e paralisações.

\section{Considerações finais}

Diante do grave problema referente à criminalidade e seu crescimento no período recente, em especial, na Bahia, este estudo buscou analisar a eficiência dos seus gastos públicos municipais com segurança, considerando 95 municípios baianos. Essa amostra foi delimitada mediante a disponibilidade de dados para os gastos públicos per capita com segurança e as taxas de criminalidade (homicídios dolosos; estupro; e roubo e furto de veículos), em 2018. Dos 95 municípios baianos selecionados, 13 deles representaram outliers, sendo, portanto, desconsiderados dessa análise.

Os resultados estimados por meio do método de Análise Envoltória dos Dados sob orientação produto revelaram que, nos modelos de eficiência técnica sob a pressuposição de retornos constantes à escala (CRS) e de eficiência de escala, mais de $90 \%$ dos municípios baianos analisados estão obtendo baixa eficiência dos gastos públicos com segurança e que cerca de $58 \%$ registraram médio grau de eficiência, quando se considera o modelo com retornos variáveis à escala (VRS).

Dos 82 municípios baianos analisados neste estudo, somente Itaberaba, localizado no Centro-Norte baiano, atingiu o máximo grau de eficiência técnica, no modelo CRS, e se destacou também como o município que menos gastou com segurança pública. Em contrapartida, Luís Eduardo Magalhães, que faz parte do Extremo Oeste baiano, foi o que mais destinou recursos para a segurança pública por habitante, em 2018, porém registrou um dos menores escores de eficiência dos gastos públicos com segurança. Portanto, constata-se que, neste caso, os municípios detentores de menores dispêndios com segurança pública estão associados aos melhores níveis de eficiência. 
Considerando o modelo VRS, os resultados mostraram que 19 municípios a mais que no modelo CRS encontram-se na fronteira de retornos variáveis à escala, mas não fazem parte da fronteira de retornos constantes, ou seja, não possuem problemas quanto ao uso excessivo de insumos, mas detêm problemas relativos à escala adotada de forma indevida. Em relação à eficiência de escala, parcela majoritária obteve ineficiência de escala, podendo ser atribuída à presença de retornos decrescentes de escala.

Em síntese, observa-se que a criminalidade e os problemas de segurança pública não se restringem apenas aos grandes centros populacionais. Tal situação requer dos formuladores de políticas públicas estratégias para debelar este problema social. Para tal, reitera-se que maiores gastos em segurança não se traduzem necessariamente em melhor qualidade do recurso investido, sendo, portanto, indispensável planejamento, tecnologia e inteligência organizacional para combater os elevados índices de criminalidade que assolam a Bahia, assim como a gestão orçamentária baseada no constante monitoramento dos resultados das políticas e dos programas implementados. Ademais, importa ressaltar, como salientado, que a criminalidade é influenciada pelas ações e atividade criminosa dos municípios circunvizinhos. Dessa forma, reconhece-se que esforços dos municípios, assim como o ente estadual e federal colaboram no combate à criminalidade no estado em estudo, bem como no Brasil.

Levando em conta que, para se alcançar êxito nas políticas de redução da criminalidade, demanda-se a atuação tanto de entes governamentais pertencentes a área da Segurança Pública das três esferas governamentais, quanto de outras áreas, como Educação, Proteção Social, Economia e Infraestrutura, sugere-se que trabalhos posteriores analisem os determinantes dos escores de eficiência dos gastos municipais com segurança pública na Bahia, assim como contemple outros estados do Nordeste e do Brasil, abordando inclusive a existência de correlação espacial entre as regiões, para expansão do debate sobre essa questão.

\section{Referências}

ARANTES, V. A.; CUPERTINO, S. A.; SILVA, E. D.; LUQUINI, R. A Segurança pública nos municípios mineiros: eficiência e alocação de recursos públicos. Revista da Faculdade de Administração e Economia, São Paulo, v. 1, n. 1, p. 128-145, 2012.

ARAÚJO, A. P. Gastos com segurança pública: uma análise nos estados mais populosos do Brasil no período de 2011 a 2014. Monografia (Ciências Contábeis). Universidade Federal do Rio Grande do Norte, 2016. Natal, RN: UFRN, 2016.

BANKER, R. D.; CHARNES, H.; COOPER, W. W. Some models for estimating technical and scale inefficiencies in data envelopment analysis. Management Science, v. 30, n. 9, p. 1078 1092, 1984. 
BARBOSA, W. F., SOUSA, E. P. Caracterização do nível de criminalidade no Ceará e seus determinantes socioeconômicos. In: Barreto, F. A. F. D; Menezes, A. S. B.; Dantas, R. F.; Albuquerque, E. L. S.; Sousa, F. J.; Gonçalves, L. C. (Org.). Economia do Ceará em Debate 2012. Fortaleza: IPECE, p. 115-141, 2012.

BECKER, G. S. Crime and Punishment: an economic approach. The Journal of Political Economy, Chicago, v. 76, p. 169-217, 1968.

BOHN, L.; DALBERTO, C. R.; ERVILHA, G. T.; GOMES, A. P. Os determinantes da eficiência dos gastos públicos com segurança nos municípios mineiros: uma análise a partir da metodologia DEA. Economic Analysis of Law Review, Brasília, v. 6, n. 1, p. 34-54, 2015. CERQUEIRA, D. et al. Atlas da violência 2019. Brasília: Rio de Janeiro: São Paulo, 2019. 106 p. Disponível em: https://www.ipea.gov.br/atlasviolencia/download/12/atlas-2019. Acesso em: 15 ago. 2020.

CERQUEIRA, D.; LOBÃO, W. Determinantes da criminalidade: uma resenha dos modelos teóricos e resultados empíricos. Texto para Discussão n. 956. Rio de Janeiro: IPEA, jun. 2003.

CHARNES, A.; COOPER, W.W.; RHODES, E. Measuring the efficiency of decision making units. European Journal of Operational Research, v. 2, n. 6, p. 429-444, 1978.

COELLI, T.; RAO, D. S. P.; BATTESE, G. E. An introduction to efficiency and productivity analysis. Norwell: Kluwer Academic, 1998.

DANTAS, F. C.; RODRIGUES, P. V. F. A.; FREITAS, A. M. M.; SILVA, D. M. Eficiência nos gastos públicos em segurança dos estados do Nordeste. Revista Econômica do Nordeste, Fortaleza, v. 47, n. 1, p. 143-157, 2016.

EHRLICH, I. Participation in illegitimate activities: a theoretical and empirical investigation. Journal of Political Economy, v. 81, p. 521-565, 1973.

ERVILHA, G. T.; BOHN, L.; DALBERTO, C. R.; GOMES, A. P. Eficiência dos gastos públicos com segurança nos municípios mineiros. Revista Econômica do Nordeste, Fortaleza, v. 46, n. 1, p. 9-25, 2015.

FARREL, M. J. The measurement of productive efficiency. Journal of the Royal Statistical Society, Series A, part III, p. 253-290, 1957.

FIRMINO, M. J. A. C. S. Testes de hipóteses: uma abordagem não paramétrica. Dissertação (Mestrado em Matemática para Professores). Universidade de Lisboa, 2015. 107 f. Lisboa, PT: UL, 2015.

FREITAS JÚNIOR, F. L.; ARAÚJO, R. J. R.; SILVA, P. E. N. T. B.; LINS, D. C. Segurança pública estadual brasileira: o que influencia seu desempenho? REUNIR: Revista de

Administração, Contabilidade e Sustentabilidade, v. 10, n. 1, p. 89-99, 2020.

KELLY, M. Inequality and crime. The Review of Economics and Statistics, v. 82, n. 4, p.530$539,2000$. 
LIMA, M. G.; BESEN, F. G.; ARAÚJO, T. V.; SERAFIM JUNIOR, V. Eficiência dos estados brasileiros na alocação dos gastos públicos na área de segurança pública com o uso da Análise Envoltória de Dados. In: Conferência Internacional em Gestão de Negócios, 2, 2017. Anais [...]. Cascavel, PR: CINGEN, 2017.

LOBO, L. F.; FERNANDEZ, J. C. A criminalidade na Região Metropolitana de Salvador. In: Encontro Nacional de Economia, 31, 2003. Anais [...]. Porto Seguro, BA: ANPEC, 2003.

MOREIRA, R. C.; FOCHEZAT'TO, A. Análise espacial da criminalidade no estado da Bahia. Revista de Desenvolvimento Econômico, Salvador, v. 3, n. 36, p. 52-80, dez. 2017.

NIELSEN, A. Não há mais lugar seguro: criminalidade avança pelo interior do País. Desafios do Desenvolvimento, Rio de Janeiro, ano. 6, ed. 52, 2009.

NOGUEIRA, L. C. B.; VIEIRA, C. R. P.; VIEIRA, B. A.; MONTEIRO, A. D. Public spending versus criminality: northeastern Brazil. Revista Brasileira de Segurança Pública, São Paulo, v. 13, n. 2, p. 12-29, ago./set. 2019.

ODON, T. I. Segurança pública e análise econômica do crime: o desenho de uma estratégia para a redução da criminalidade no Brasil. Revista de Informação Legislativa, Brasília, v. 218, n. 55, p. 33-61, abr./jun. 2018.

PEREIRA FILHO, O. A.; TANNURI-PIANTO, M. A.; SOUSA, M. C. S. Medidas de custoeficiência dos serviços subnacionais de segurança pública no Brasil: 2001-2006. Economia Aplicada, São Paulo, v. 14, n. 3, p. 313-338, 2010.

REBELO, S.; MATIAS, F.; CARRASCO, P. Aplicação da metodologia DEA na análise da eficiência do setor hoteleiro português: uma análise aplicada às regiões portuguesas. Tourism $\boldsymbol{\&}$ Management Studies, v. 9, n. 2, p. 21-28, 2013.

RODRIGUES, A. M. G.; BRITO, M. A.; SOUSA, E. P. Os municípios baianos estão alocando eficientemente seus recursos destinados à educação básica? Uma análise sob a ótica do método DEA. Revista de Desenvolvimento Econômico, Salvador, v. 2, n. 40, p. 502-527, ago. 2018.

SANTOS, C. A. P.; CASAGRANDE, D. L.; HOECKEL, P. H. O. "Teoria Econômica do Crime": dos pressupostos acadêmicos à empiria do dia a dia na vida de ex-presidiários de Santa Maria, RS. Economia e Desenvolvimento, Santa Maria, v. 27, n. 2, p. 308-325, jun./dez. 2015.

SANTOS, I. G.; GONTIJO, J. G. L.; AMARAL, E. F. L. A política de segurança pública no Brasil: uma análise dos gastos estaduais (1999-2010). Revista Opinião Pública, São Paulo, v. 21, n. 1, p. 105-131, 2015.

SANTOS, M. J.; KASSOUF, A. L. Estudos econômicos das causas da criminalidade no Brasil: evidências e controvérsias. Revista Economia, Brasilia, DF, v. 9, n. 2, p. 343-372, 2008.

SCHULL, A. N.; FEITÓSA, C. G.; HEIN, A. F. Análise da eficiência dos gastos em segurança pública nos estados brasileiros através da Análise Envoltória de Dados (DEA). Revista Capital Científico, v. 12, n. 3, p. 91-105, 2014. 
SECRETARIA DE SEGURANÇA PÚBLICA - SSP. Estatística 2018. Disponível em: http://www.ssp.ba.gov.br/modules/conteudo/conteudo.php?conteudo=97. Acesso em: 24 jun. 2020.

SHIKIDA, P. F. A. Economia do crime: teoria e evidências empíricas a partir de um estudo de caso na Penitenciária Estadual de Piraquara (PR). Revista de Economia e Administração, São Paulo, v. 4, n. 3, p. 315-342, jul./set. 2005.

\section{SISTEMA DE INFORMAÇÕES CONTÁBEIS E FISCAIS DO SETOR PÚBLICO} BRASILEIRO - SICONFI. Tesouro nacional. Disponível em: https://siconfi.tesouro.gov.br/siconfi/pages/public/consulta finbra/finbra list.jsf. Acesso em: 24 jun. 2020.

SOARES, A. M. C. O acúmulo da violência e da criminalidade na sociedade brasileira e a corrosão dos direitos humanos. Revista Interdisciplinar de Direitos Humanos, Bauru, v. 2, n. 3, p. 161-189, jul./dez. 2014.

SOARES, T. C.; ZABOT, U. C.; RIBEIRO, G. M. Índice geral de criminalidade: uma abordagem a partir da análise envoltória de dados para os municípios catarinenses. Leituras de Economia Política, Campinas, v. 13, n. 2 (19), p. 89-109, dez. 2011.

SOUSA, M. C. S.; CRIBARI-NETO, F.; STOSIC, B. D. Explaining DEA technical efficiency scores in an outlier corrected environment: the case of public services in Brazilian municipalities. Brazilian Review of Econometrics, v. 25, n. 2, p. 287313, 2005. 